\title{
Discussions on Development of Cultural Tourism Industry in Region at the Source of the Pearl River
}

\author{
Jingfeng Wang \\ School of economics and management, Qujing Normal University, Qujing Yunnan, 655011, China
}

Key words: Source of the Pearl River, Cultural tourism, Development.

\begin{abstract}
The Pearl River is one of the three large inland rivers of China. The region at the source of the Pearl River is rich in natural landscape resources and human landscapes, has a profound historical and cultural foundation, and is distinctively featured by minority folk-custom, all of which are advantageous conditions for the development of cultural tourism industry. Yet the development situation of cultural tourism industry at the source of the Pearl River is still less than satisfactory. Only by transformation and upgrading of scenic region at the source of the Pearl River, and development of minority folk-custom-themed the Three Kingdoms History-themed cultural tourism, and cultural heritage tourism products, the cultural tourism industry at the source of the Pearl River can have more development opportunities.
\end{abstract}

\section{Overview of the Pearl River and of Its Source}

The Pearl River is one of the three inland rivers of China. By streamflow, the Pearl River is the second largest inland river in China, second only to the Yangtze River; by length, the Pearl River is the third largest inland river in China, following the Yangtze River and the Yellow River. The main stream of the Pearl River is $2320 \mathrm{~km}$ long in total, the basin area is $446,768 \mathrm{~km}^{2}$ [1] , its river basin stretches over Yunnan, Guizhou, Guangxi, Hunan, Jiangxi, Guangdong, Hong Kong and Macao, and it flows into the South China Sea from the $8^{\text {th }}$ estuary in the Pearl River Delta. ${ }^{[2]}$

The Pearl River originated from the cave of debounchure at the eastern foot of Mountain Maxiong in Zhanyi district of Qujing city in Yunnan. The Pearl River is the only one originating from a cave among the inland rivers in China. The cave of debounchure at the source of the Pearl River is divided into two levels. In dry season, water flows out from the lower cave only, and from both in rainy season. In rainy season, a water fall is formed, very spectacular. ${ }^{[3]}$ The Mountain Maxiong at the source of the Pearl River is the watershed between the Niulan River of the Yangtze River and the Nanpan and Beipan Rivers of the Pearl River, and also is the headstream of the Nanpan (main stream) and Beipan (tributary) Rivers of the Pearl River, where there appears a natural wonder of "one water drops in three years, and one mountain divides two rivers". The Mountain Maxiong is heavily forested, and rich in plant resources, of which the forest coverage reaches above $90 \%$, and where the mountains, water, trees, caves and flowers constitute beautiful sceneries. The Pearl River source scenic region in Mountain Maxiong has become a well-known national forest park, national water conservancy scenic area, and provincial tourist attraction. The scenic region covers an area of $12 \mathrm{~km}^{2}$, and it was rated as national AAAA tourist attraction in 2005.

The region of the Pearl River source can be divided into three levels by geographical scope from small to large. The first level refers to the place of the Pearl River source-Qujing city in Yunnan province, which includes 6 counties, 2 districts and 1 city under Qujing city; the second level refers to the area of the basin perimeter of the Nanpan River (the main stream of the Pearl River) in Yunnan section, which includes Qujing city, Kunming city, Yuxi city, Honghe prefecture, and Wenshan 
prefecture of Yunnan; the third level refers to all regions in the basin perimeter of the Nanpan River and the Beipan River, which includes Qujing city, Kunming city, Yuxi city, Honghe prefecture and Wenshan prefecture in eastern Yunnan, Qianxinan prefecture, Liupanshui city and Anshun city in western Guizhou, and Baise city in northwest Guangxi. The Pearl River source region referred to herein means the first level.

\section{Advantages and Problems of Development of Cultural Tourism Industry in the Pearl River Source Region}

\section{Advantages}

The Pearl River source region is rich in natural landscape resources and human landscapes, has a profound historical and cultural foundation, and is distinctively featured by minority folk-custom, which provide good basic conditions for the development of cultural tourism industry in the Pearl River source region.

Inherent Popularity of the Pearl River Source

From the aspects of length and streamflow, the Pearl River ranks top three among the inland rivers in China, and first in south China. In the Pearl River Delta in the downstream, Guangdong well-known as the front position of implementing the policy of reformation and opening up, Hong Kong rated as the "Oriental Pearl” and the Macao Special Administrative Region are located, which make the Pearl River be renowned both at home and abroad. Hence, the Pearl River source region also enjoys the advantage of its inherent popularity.

An Almost Perfect Combination of the Source of River with that of Human Civilization

In 1987, people found fossils of lower jawbone of ancient humans in the Neolithic Age which can be dated back to about five thousand years ago in the Zhuyuan Cave at the source of the Pearl River, indicating that there were human activities as early as five thousand years ago at the source of the Pearl River. Besides, the Paleolithic ancient cultural relics of the Fuyuan River which ranks first in the "Ten New Archaeological Discoveries in China in 2006" discovered in the region at the source of the Pearl River has stopped a gap in Chinese archaeology of human activities dating back to 40,000 to 100,000 years ago, and indicated there was the flame of human civilization in the region at the source of the Pearl River as early as 100,000 years ago, and it was one of the cradles of ancient civilization. The source of river and that of human civilization were combined in an almost perfect way there, which undoubtedly distinguishes the development of cultural tourism industry in the Pearl River source region in respect of history and culture.

The source region of the Pearl River is the only one place suitable for development of mass tourism among the source regions of the three inland rivers in China.

Visiting the source of famous rivers is the dream of many people. Chinese people have been being educated to "never forget where water comes from" since ancient time, and people always tend to yearn for and indulge in reveries about the source of great rivers. Among the source regions of the three inland rivers in China, those of the Yangtze River and Yellow River still remain under controversy. In the 1970s, the Changjiang Water Resources Commission, through investigation and study, held that the Tuotuo River originating from the Jianggendiru Glacier at the foot of the Geladandong Mount of the Tanggula Mountains is the authentic source of the Yangtze River, in 2008, through the Scientific Investigation of the Three River Resources organized by Qinghai Provincial Government and directed by the State Bureau of Surveying and Mapping, it was proposed that the Dangqu River is the authentic source of the Yangtze River; in 1952, the Yellow River Conservancy Commission determined Maqu to be the authentic source of the Yellow River; in 1978, the People's Government of Qinghai Province determined Kariqu to be the authentic source of the Yellow River; in 1985, based on the historical traditions and opinions from all sides, the Yellow River Conservancy Commission determined Yueguzongliequ to be the main stream of the Yellow River in the upper reaches. It is thus clear that Maqu, Yueguzongliequ and Kariqu all could be the authentic source of 
the Yellow river. ${ }^{[4]}$ Only after the cave of debounchure at the eastern foot of Mountain Maxiong in Zhanyi district of Qujing city in Yunnan was determined to be the authentic source of the Pearl River in 1985, there is no controversy at all. Besides, the natural conditions in the region of source of three rivers in Qinghai where the Yangtze River and Yellow River originated from are harsh, and difficult to access to. Only the source of the Pearl River is accessible. Therefore, the Pearl River source is the only one among the sources of the three inland rivers in China suitable for development of mass tourism, which naturally become the first choice of Chinese people, in particular of people living by the Pearl River, to realize the dream of exploration of river sources.

Historical and Cultural Resources

There were human activities at least 100,000 years ago at the source of the Pearl River. The source region of the Pearl River was a region developed and formed early in Yunnan. Since the formation of Wei County in Qujing in the second year of the period of Yuanfeng (109 BC), more than two thousand years has lapsed. In the five hundred odd years from the third year (225AD) of the period of Jianxing of Shuhan Kingdom after Zhuge Liang's Southern Campaign in the Three Kingdoms Period to the seventh year of the period of Tianbao (748AD) when the Kingdom of Nanzhou annihilated Cuan, Qujing had been being the political, economic and cultural center in the middle south region (including the whole Yunnan, south Sichuan, and part of western Guizhou), where the brilliant Cuan Culture inheriting the ancient Yunnan culture and enlightening the Nanzhou and Dali cultures emerged. ${ }^{[5]}$ There was a story of “capturing and releasing Meng Huo seven times” during Zhuge Liang's Southern Campaign happening in Qujing. Hence, there are stories and remains about Zhuge Liang in many places in Qujing.

Minority Folk Custom and Culture

Although the population of minority in the source region of the Pearl River is small, their folk custom and culture are distinctive. Luoping County is the main habitation of the Buyi nationality, and the Changdi Buyi Village and Lubuge Buyi Miao Village in Luopin are the only two settlements of the Buyi nationality in Yunnan province. The Gugan Shui Village in Fuyuan County is the only one Shui Village in Yunnan province. In 2013, the Lazhe Village in Lubuge Town in Luoping and the Heier Village in Shizong county were rated as the "Most Attractive 30 Villages in Yunnan”.

\section{Problems}

Though the source region of the Pearl River enjoys many advantages for developing cultural tourism industry, the development situation of cultural tourism industry is less satisfactory. The main problems include: small scale, insufficiency of construction fund input and marketing publicity, low fusion of tourism industry with cultural industry, weak driving effect of tourism on cultural industry and promotion of culture on tourism industry, low development level of tourism products, and low cultural taste of scenic spot construction, etc.

\section{Measures for and Suggestions on Development of Cultural Tourism Industry in Source Region of the Pearl River}

\section{Transformation and Upgrading of the Pearl River Source Scenic Region}

The construction of the Pearl River source scenic region, the core scenic region and symbol scenic region in the source region of the Pearl River, plays a vital role in the development of cultural tourism in the source region of the Pearl River. The development situation of the Pearl River source scenic region greatly restricts the development of cultural tourism industry of the Pearl River source, so the transformation and upgrading of the Pearl River source scenic region should be launched as early as possible.

The primary task of the transformation and upgrading of the Pearl River source scenic region is to redesign the origin exploration route of the scenic region. Since the Pearl River source is a representative "holy land" of river source culture in China, tourism in the Pearl River source should 
be able to satisfy the cultural and psychological demand of pilgrimage of people. Visiting to the Pearl River source should be the hottest point of tourism in the Pearl River source, and the design of origin exploration naturally should become the priority among priorities of scenic spot construction. The existing origin exploration route, however, is the "biggest failure" in the construction of the whole Pearl River source scenic region. According to the existing origin exploration route, we can enter the gate of the scenic region, turn right and pass through a hundred-meter flat path, and arrive at the cave of debouchure. This route is too simple, dull, and boring, lacks imagination and cultural tastes, and tend to disappoint tourists. The re-design of the origin exploration route should follow the principles of "tracing a river upwards, experiencing twists and turns, setting suspense, and then arriving the source”, for which the artistic conception as described in the Peach-Blossom Spring of Tao Yuanming can be properly learned. It is unnecessary to seek a magnificent visual effect in the design of the origin exploration route, efforts must be done to realize a beautiful artistic conception and a long aftertaste, make the process of origin exploration a mysterious experience, and let tourists enjoy soul washing, sublimation and spiritual happiness while realizing the dream of origin exploration. The construction of the origin exploration route should be carried out to highlight this theme, and bear no unnecessary artificial trace.

Besides, the scenic region can be constructed to highlight the elements of Chinese river source culture of never forgetting where water comes from and long-standing and well-established, integrate the historical and cultural contents of the source region, and include the idea of green ecology running throughout the scenic region construction and river source tourism, to raise the cultural taste of the Pearl River source scenic region.

\section{Development of Minority Folk-Custom-themed Cultural Tourism}

Although the population of minority in the Pearl River source region is small, the place has its own comparative advantages of minority folk-custom-themed culture. For example, Luoping County is the main habitation of the Buyi nationality in Yunnan province, and the Changdi Buyi Village and Lubuge Buyi Miao Village in Luopin are the only two settlements of the Buyi nationality in Yunnan province; the Gugan Shui Village in Fuyuan County is the only one Shui Village in Yunnan province. Besides, the settlements of Buyi, Shui, Zhuan people and other minorities in that place mostly are near the mountain and by the river, and folk-custom culture is always intertwining with beautiful natural landscapes, which are advantages for the development of cultural tourism industry.

For the development of minority folk-custom-themed cultural tourism, focus should be laid on the Buyi people custom culture in Luoping, the Zhuang people custom culture in Shizong, and the Shui people custom culture in Fuyuan, and other local and advantageous items.

\section{Development of the Three Kingdoms History-Themed Cultural Tourism}

Everyone knows about the story of “capturing and releasing Meng Huo seven times” of Zhuge Liang, and the story happened in Qujing. There are stories and remains related to Zhuge Liang, which provide a lot of resources and materials for the development of the Three Kingdoms History-themed historical and cultural tourism.

Presently, the Three Kingdoms History-themed historical and cultural tourism project under progress in Qujing is one of the ten historical and cultural tourism projects in Yunnan province, which is located in Malong County in Qujing. The project, in the principle of "originating from and surpassing the history", and reflecting the theme of "rooting in the middle south, and infusing Qujing”, has vividly reproduced over 500-hundred year of history from Zhuge Liang's South Campaign to the thriving of Cuan Culture when Qujing had been taken as the political, economic and cultural center of Yunnan, displayed a beautiful scroll of national fusion, unity and progress in the borderland in Yunnan, built a large-scale comprehensive tourism project integrating historical and cultural ancient town, leisure holiday resort, and modern new city with sufficient tourism elements and in various operational types. Once the project is completed, supplemented with the Three 
Kingdoms History culture remains, a Three Kingdoms History-themed tourism product system can be formed in Qujing.

\section{Development of Cultural Heritage Tourism Products}

The source region of the Pearl River has a long history, and is rich in ruins of ancient organisms and ancient humans, which provide abundant resources for the development of cultural heritage tourism there. There are 9 national key cultural relic protection sites in Qujing. The Paleolithic ancient cultural relics of the Fuyuan River which ranks first in the "Ten New Archaeological Discoveries in China in 2006" has stopped various gaps in Chinese archaeology of human activities dating back to 40,000 to 100,000 years ago, where the oldest Paleolithic stone-paved ground known as the earliest "interior decoration" was discovered; the Paleolithic ancient cultural relics indicated that there existed the flame of human civilization in the source region of the Pearl River as early as in 100,000 years ago, and is one of the source places of ancient civilization. The Batatai ancient tomb group in Qiling district and the Luohan Mount ancient tomb group reflect that the civilization in the source region of the Pearl River reached a high level as early as in the pre-Qin dynasty and the Eastern Han dynasty. The Cuanlongyan stone tablet and Cuanbao son stone tablet (parent and son Cuan stone tablets) are not only the "treasure" in Chinese calligraphy circle, but also are physical remains of Cuan Culture. There left lots of relics of communication between Yunnan and Central Plains since the building of the Wuchi Road in the Qin dynasty on the post road of Kedu Pass in Xuanwei. These national key cultural relic protection sites all can be taken as main cultural resources for the development of tourism and cultural industry, based on which a cultural heritage tourism product system can be built in the source region of the Pearl River.

Besides, the Luoping biogroup, a national geopark, also should be developed as soon as possible for scientific investigation and science popularization, and become a new force of the cultural tourism industry of the Pearl River source.

\section{Acknowledgments}

This paper is a major philosophy and social science project of Qujing City, titled "Research on Development of Cultural Tourism Industry at the Pan-source of the Pearl River" and numbered ZD201504.

\section{References}

[1] Cai Wenqing. The Pearl River Is Identified as the Second Large Inland River in China [N]. Beijing Evening News, 2012-2-23 (20).

[2] Guangdong Map Publishing House. Tourist Map Altas of the Pearl River [M].Guangzhou: Guangdong Map Publishing House, 2001: 1.

[3] Yang Guihua, Yang Yuehua. Research on Development and Design of Ecotourism Products of The Pearl River Source [J]. Thinking, 1997, (6): 44-48.

[4] Zhang Jinlin, Chen Guozhou. New Interpretations of Geographical Location of the Sources of the Yangtze River and the Yellow River [EB/OL]. http://www.qh.xinhuanet.com/2009-07/16/content_17112601.htm.

[5] Zhao Xiaohe. Modernization of Qujing. China [M].Kunming: Yunnan People's Publishing House, 2006: 1-7. 